\title{
Seismic Performance of Bridges with Different Pier Heights: Longitudinal Analysis of an Existing Bridge
}

\author{
João Coimbra Sampayo and Carlos Sousa Oliveira \\ Instituto Superior Técnico, Universidade de Lisboa (Superior Technical Institute of Lisbon University), Lisbon 1049-001, Portugal
}

\begin{abstract}
This paper is dedicated to the study of the seismic performance of an existing RC (reinforced concrete) bridge localized in a region of moderate seismicity. The bridge has six spans and piers with very different heights, three of which are monolithically connected to the deck. To understand the roles of the different pier sizes in the overall behavior, several analyses were carried out in the longitudinal direction: (1) linear dynamic approach; (2) non-linear static approach; (3) non-linear dynamic approach. Linear dynamic analysis was made in order to design the bridge for the ultimate limit state considering the largest value of the ductility factor. No safety verification was made for the other loads. Using non-linear static analyses, sensitivity was performed to check the influence of reinforcement quantities of each pier on the overall behavior of the bridge under Lisbon seismic action. For the non-linear dynamic approach, a series of strong motion records compatible with the EC-8 spectrum for Lisbon area were generated. The very same combinations of reinforcement quantities were studied. Comparisons between static and dynamic non-linear analysis were made to confirm the validity of the first one in the case under analysis, where the period of vibration is quite high.
\end{abstract}

Key words: RC bridge, seismic behavior, linear methods, non-linear methods.

\section{Introduction}

Till mid-fifties of the last century, the effect of the seismic action on structures was represented by static lateral forces with value equivalent to a percent of the existing vertical loads. This method was considered not sufficient to characterize the seismic behavior and, consequently, other methods based on the kinematic and dynamic modeling of the structures were developed. Non-linear analyses were recommended after understanding that the linear methods by themselves could not represent the reality in many instances, even though linear modeling together with the concept of ductility is still in use in the majority of the design offices. At that time, a set of studies were made in order to study in detail the cycle behavior of steel and concrete, and the influence of various seismic parameters of the seismic action namely the PGA (peak ground acceleration), the PGV (peak ground velocity), the frequency content and the duration.

Corresponding author: João Coimbra Sampayo, scholar grantee, research fields: earthquake engineering and dynamics. E-mail: joaocsampayo@gmail.com.
In the behavior of the structure, we should explore the ductility, not only to support the displacements but mainly the energy accumulated in the structure. In the past Portuguese code [1] and in the recent developed EC-8-1 [2], the linear methods are recommended together with the use of behavior coefficients. However, with the introduction of high capacity computations, it is possible today to analyze more complex structures, giving rise to the non-linear static and dynamic studies. In particular, the static methods, among which is the so-called N2, when applied to regular structures, present results which are quite adequate so they initiate their exploitation in design (as recommended in EC-8). Nevertheless, for irregular structures, they do not have the capacity to simulate all the conditioning constrains. In this paper where an irregular structure with a pier of high stiffness is modeled, this method is tested against a more general method of non-linear dynamic analysis and results are confronted both with non-linear static and with just linear methods. In this way, it is possible to check how far the more sophisticated method comes from other methods. 
The bridge has a total length of $440 \mathrm{~m}$ with six spans: the central two with $100 \mathrm{~m}$, two with $75 \mathrm{~m}$ and the two connecting to the embankments with $45 \mathrm{~m}$. The deck, a monolithically multi-supported beam, has a hollow box-girder of variable height. The three central piers are monolithically connected to the deck and are 62.0, 67.4 and $24.8 \mathrm{~m}$ high, respectively. The cross-section of these piers is typically a hollow rectangle reinforced at the corners and with variable dimensions in the region close to the base. The other spans are supported by supporting devices at the piers connections and embankments. Fig. 1 presents the profile of the bridge and the geometric characteristics of typical cross-sections.

Following the initial design, a concrete C40 and steel class A400 were used in this analysis. The main properties of these materials which were used in the linear analysis, are presented in Table 1 (values already reduced as in design), while the non-linear constitutive relations for those materials are based in Mander [3] for concrete and Manegotto [4] for reinforcement.

\section{LDA (Linear Dynamic Analysis)}

The linear analysis was performed with the SAP2000 software [5], strictly following the original drawings. The deck and the piers were modeled with "beam elements" with a discretization of $3.5 \mathrm{~m}$ for Pier 4 and $5 \mathrm{~m}$ for all other elements. Piers were built-in at the foundation, a solid rock geological complex. In this analysis, all piers were supposed monolithically connected to the deck. The concrete Young modulus value is reduced to $50 \%$ to consider the exterior cracking of concrete. Two main modal shapes were identified in the analysis performed on the longitudinal and vertical direction only: one associated with the longitudinal displacement of the deck with a period of $T=1.76 \mathrm{~s}$, and the local mode of Pier 3 with a period of $T=0.33$ s. These values were validated by in-situ ambient measurements provoked by the vibration of passing cars and vans.

The bridge was considered as belonging to importance Class IV (corresponding to an importance factor $\gamma=1.95)$ located in a soil Type A [2].

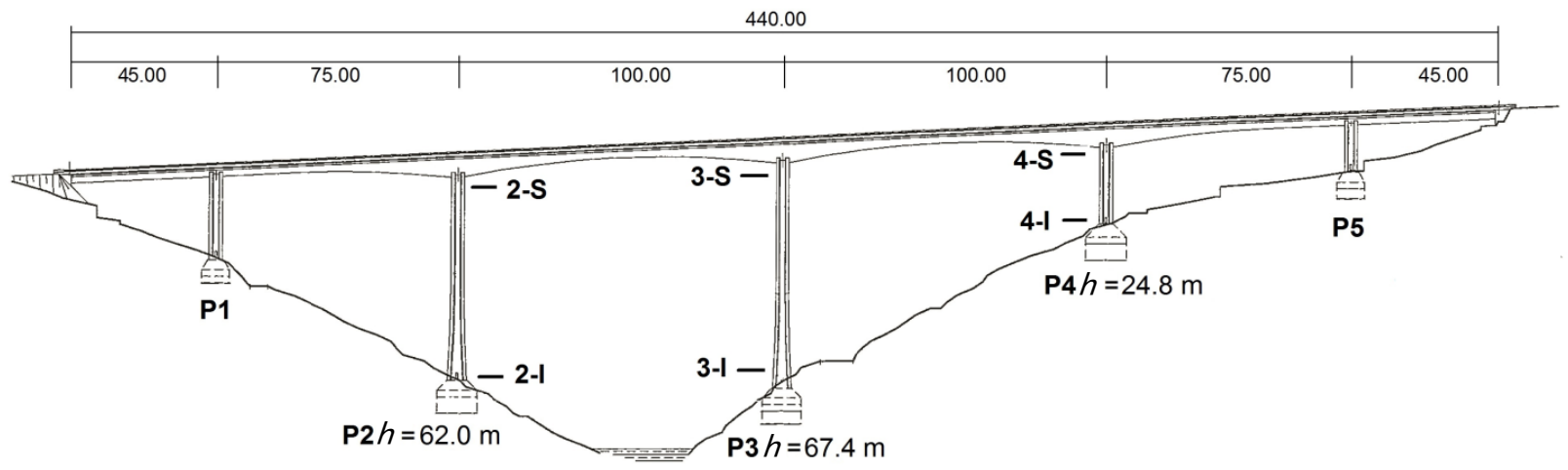

(a)

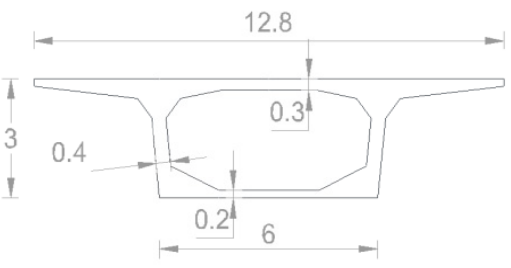

Mid-span section

(b)

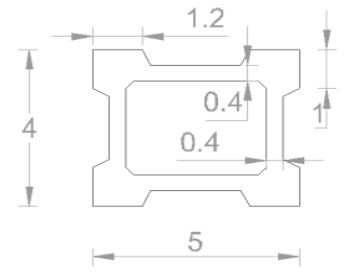

2-S, 3-S, 4-S and 4-I

(c)

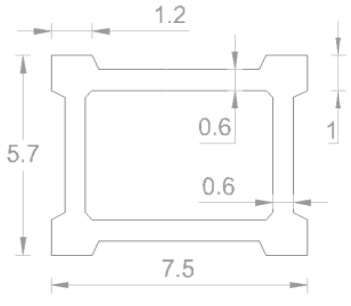

2-I and 3-I

(d)

Fig. 1 Profile of the bridge and the geometric characteristics of cross-sections: (a) bridge overall; (b) mid-span section; (c) piers superior sections; (d) piers inferior sections (units in $\mathbf{m}$ ). Source: credits by Armando Rito. 
Table 1 Material's properties used in the linear analysis.

\begin{tabular}{llll}
\hline Material & $E(\mathrm{GPa})$ & $f_{k}(\mathrm{MPa})$ & $f_{c d}(\mathrm{MPa})$ \\
\hline C40 & 35 & 40 & 26.7 \\
A400 & 200 & 400 & 347.8 \\
\hline
\end{tabular}

In the design of the steel bars, the behavior factor $q=$ 3.0 was assumed and the bridge was studied for three different zones of increasing seismicity starting from the original situation: Azambuja with a lower hazard than Lisbon, Lisbon and Aljezur with a higher hazard. Fig. 2 shows the acceleration design spectra ( $\mathrm{Se}$ ) corresponding to these locations [6].

The forces directly obtained from SAP2000 were added to the ones due to the second order effects $\left(M_{E d}\right.$, $N_{E d}$ ). The analysis of the transversal section is made through a simple model of an equivalent binary moment where the group of core-flange supports all the bending $\left(F_{M}=M_{E d} / z\right)$ and axial $\left(F_{N}=N_{E d} / 2\right)$ forces as shown in Fig. 3.

By analyzing the efforts in Pier 4, it was possible to determine the seismic action in Lisbon, such as the one which can exploit better the ductility of that pier due to percent of reinforced bars of $\rho_{L}=1.8 \%$. The displacement of the deck for this case is $\delta_{E d}=0.19 \mathrm{~m}$ and the basal shear $V_{E d}=12,893 \mathrm{kN}$ which corresponds to a seismic coefficient $\beta=8.3 \%$. Table 2 presents the design efforts, where "I" and "S" represent the inferior and superior critical sections of each pier.

The piers are designed according to EC-8-2 based on capacity design considering an over-strength factor of $\gamma_{0}=1.35$. The length of the critical zone is $l_{h}=4 \mathrm{~m}$ for both the upper and the lower zones. The steel bars are 192 1932 and 176Ф32, respectively, in the lower and upper critical zones. These quantities are distributed to the flange and the core. In the connecting zone, the steel percent is reduced until approximately mid height where the steel is 30Ф32. Dealing with hollow sections, EC-8-2 [7] does not require confinement, however, in the cores a minimum quantity of steel for outer stirrups and four stirrups in the inner part in both directions, all $\Phi 12 / / 0.1$. To warrant an adequate shear safety in the connection between cores and webs, an additional

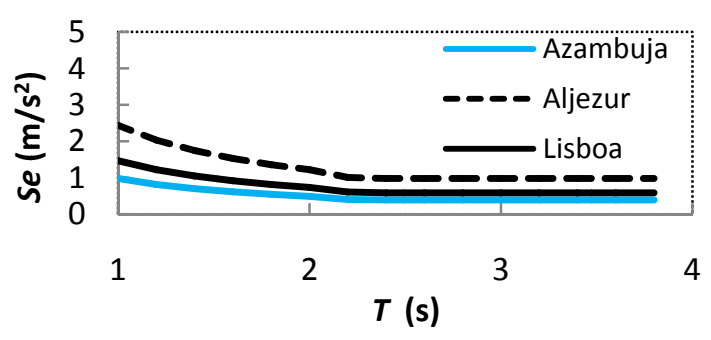

Fig. 2 Design response spectrum.

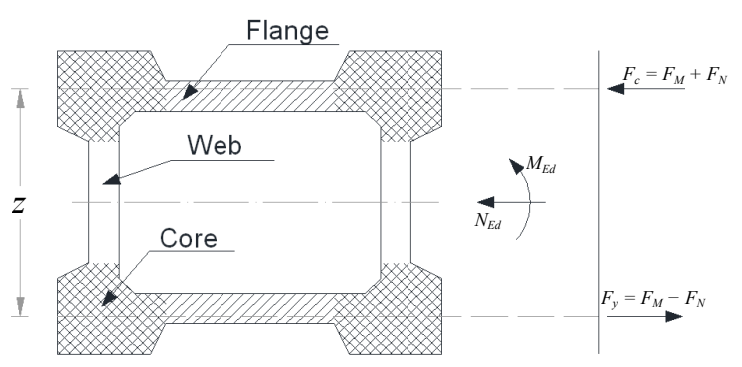

Fig. 3 Model of an equivalent binary.

Table 2 Forces demand in critical sections.

\begin{tabular}{lllll}
\hline Demand & $2-\mathrm{S}$ & 2-I & $4-\mathrm{S}$ & $4-\mathrm{I}$ \\
\hline$V_{E}(\mathrm{kN})$ & $1,372.0$ & $1,972.3$ & $9,037.8$ & $9,252.1$ \\
$N_{E d}(\mathrm{kN})$ & $27,936.5$ & $46,139.4$ & $27,815.5$ & $33,932.3$ \\
$M_{E d}(\mathrm{kN} \cdot \mathrm{m})$ & $59,059.2$ & $80,217.6$ & $135,577.8$ & $119,250.85$ \\
\hline
\end{tabular}

reinforcement with double stirrups $\Phi 16 / / 0.1$ in the critical zones and $\Phi 12 / / 0.10$ elsewhere. In other piers, a longitudinal steel of $64 \Phi 25$ was applied along all height.

\section{NLSA (Non-linear Static Analysis)}

Using the non-linear software SeismoStruct [8], a static analysis of the structure was made for the ground motion of Lisbon. To proceed with this software, several adaptations were required to represent the cross-sections by fiber areas. The deck was modeled as in SAP2000 in such a way to keep two conditions: (1) equal displacement; (2) equal stiffness rotation, at the top of piers. To achieve that, the elements of the deck between piers are considered with the same flexure stiffness as in SAP2000. The spans outside and the central spans are modeled with rotation springs. The masses associated directly to Piers 2, 3 and 4 are applied as concentrated masses in the upper part of each one. The remaining masses are applied at a point 
outside showing identical displacement to the displacement of the top of piers.

Piers cross sections are modeled as an equivalent section that the program has in its library. Among the possibilities, the option was to use an $\mathrm{H}$ shape due to the large area far from the center, keeping in mind that only the longitudinal direction of the bridge was under study.

The equivalent geometry of each section was determined in such a way to warrant the same transversal area and the same flexure inertia. This can be reached fixing the height $(h)$ and the web width $\left(w_{e q}\right)$ and changing the flange width $(b)$ and thickness $(y)$ of the equivalent section as shown in Fig. 4. We should note that the plastic behavior of both sections is similar. However, due to the large variation of Young modulus along its length, the quantity of area of fibers further located is a factor that may jeopardize the equivalence process of sections once the equivalent section presents larger areas of fibers further located than the original section.

In order to study the sensitivity of distribution of fibers in the lateral stiffness, in the individual behavior of each pier and the state of stress-extension of the critical section, four different models of longitudinal steel distribution were created. The steel used in each pier was the one obtained with the linear model for the three piers described above. The name attributed to each case reflexes the amount of reinforcement applied as shown in Table 3, being $b$ the lowest steel case and $A$ the highest. The table also presents the reasons for the different choices and the expected results.

The target displacement for each above referred model subjected to seismic loading is computed using the N2 approach [9], making use of the simplification of the system into an equivalent degree of freedom. The equivalent period $T_{e q}$ is determined equating the energy accumulated and the ultimate displacement $\delta_{u}$ by both the original and the equivalent system (assuming an elasto-plastic behavior defined by yielding displacement $\delta_{y}$ and corresponding base shear $V_{e l}$ ).
The equivalent mass $m_{e q}$ is associated with the mass which actively contributes to the fundamental mode shape of the bridge in the longitudinal direction. That is the mass of the deck plus the masses of the piers above their inflection points. $T_{e q}$ and $m_{e q}$ leads to tangent rigidity of the equivalent system $K_{e q}$ and elastic acceleration $S_{a e}$. For flexible structures, the target displacements developed by the structure $\delta_{o b}$ and by the equivalent single degree of freedom $\delta_{e l}$ are identical. The latter is obtained from the ADRS (acceleration displacement response spectrum) as shown in Fig. 5, where $S_{a}$ is the acceleration spectrum and $S_{d}$ is the displacement spectrum. The coefficient $q_{N 2}$ between the total base shear in the elastic and in the original models reflects the ductility capacity of the bridge and it increases with the increase of the stiffness of the secondary piers, and mainly with the decrease of stiffness of secondary piers. The same statement can be held about the value of $T_{e q}$. As such, the decrease of the equivalent period is associated with higher stiffness and corresponding proximity of a rigid-perfectly plastic behavior, which is an ideal situation as far as energy dissipation is concerned.

The plastic factor $f_{p l}$ was introduced to relate the ultimate secant rigidity to the tangent rigidity $\left(f_{p l}=\right.$ $\left.K_{u l} / K_{e q}\right)$. Lower participation of the secondary piers leads to an increase of the plastic factor $f_{p l}$ and, consequently, the restrain of the same displacements with larger capacity for energy dissipation. Stiffness of Pier 4 does not influence this factor. Table 4 presents in a compact format the values obtained for each model.

The b.b.A. model is the one shorter equivalent period and is the sole that presents a target displacement lower

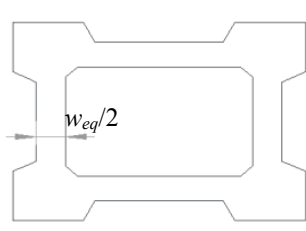

(a)

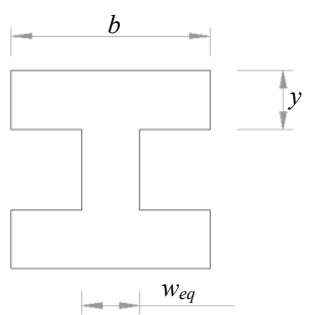

(b)
Fig. 4 Determination of equivalent section: (a) original section; (b) equivalent section. 
Table 3 Reinforcement distribution for button section of each pier (units in $\mathbf{m}$ ).

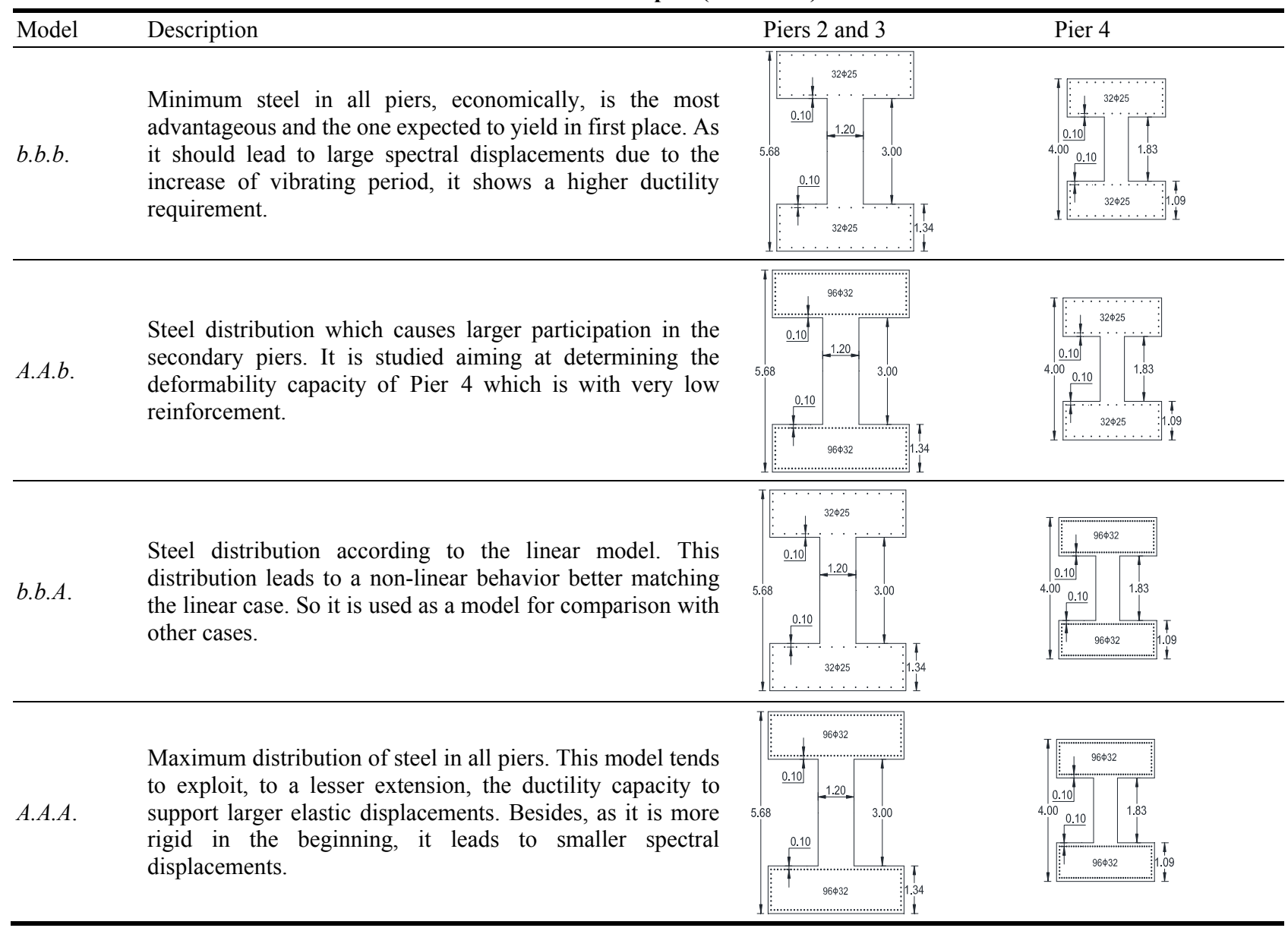

Table 4 Target displacement, plasticity factor and behavior factor.

\begin{tabular}{llllllll}
\hline Model & $K_{e q}(\mathrm{kN} \cdot \mathrm{m})$ & $\delta_{u}(\mathrm{~m})$ & $V_{e l}(\mathrm{kN})$ & $\delta_{o b}(\mathrm{~m})$ & $V_{o b}(\mathrm{kN})$ & $f_{p l}$ & $q_{N 2}$ \\
\hline b.b.b. & 126,464 & 0.296 & 28,110 & 0.222 & 11,707 & 3.12 & 2.40 \\
A.A.b. & 106,396 & 0.294 & 23,649 & 0.222 & 13,237 & 2.20 & 1.79 \\
b.b.A. & 136,880 & 0.456 & 29,691 & 0.217 & 18,506 & 3.18 & 1.60 \\
A.A.A. & 115,512 & 0.452 & 25,675 & 0.222 & 20,117 & 2.21 & 1.28 \\
\hline
\end{tabular}

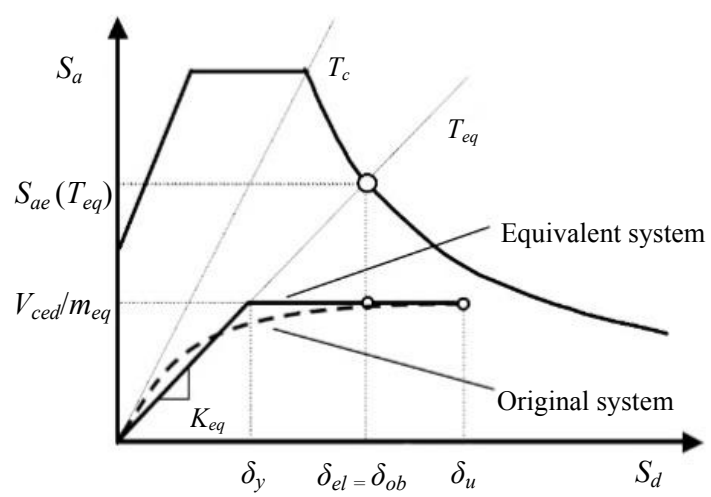

Fig. 5 Determination of target displacement by the N2 approach. than all the others. The difference is lower than $3 \%$ which is considered negligible.

The stiffness of the secondary piers does not influence the value of first yield which always occurs in Section 4-I. For this reason, the stage of the structure is almost exclusively attributed to Pier 4 . In the next stage, the secondary piers with higher stiffness gradually get a higher participation, allowing a considerable increase in the structural load capacity. On the other hand, the models with secondary piers with low reinforcement do not increase the capacity in the post-yielding stage. 


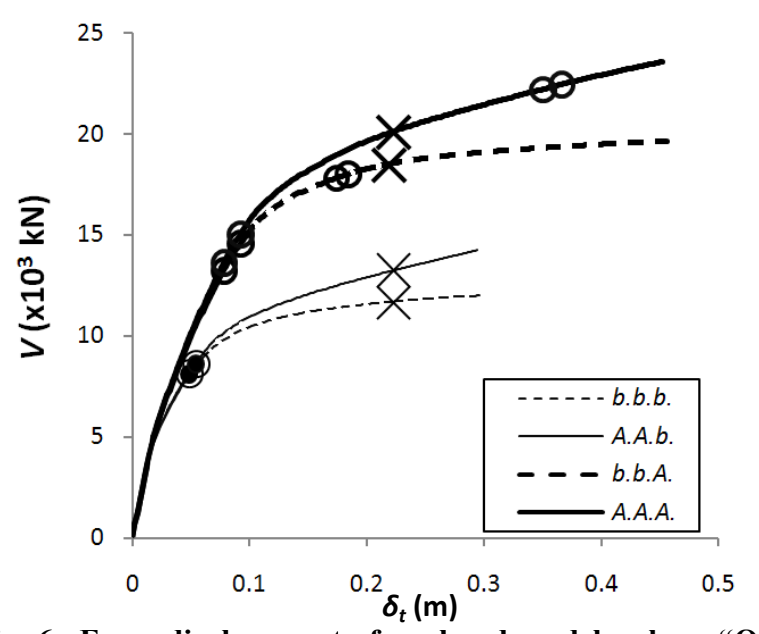

Fig. 6 Force-displacement of analyzed models where "O" represents yielding of a section and " $\mathrm{X}$ " represents the target displacement $\delta_{o b}$.
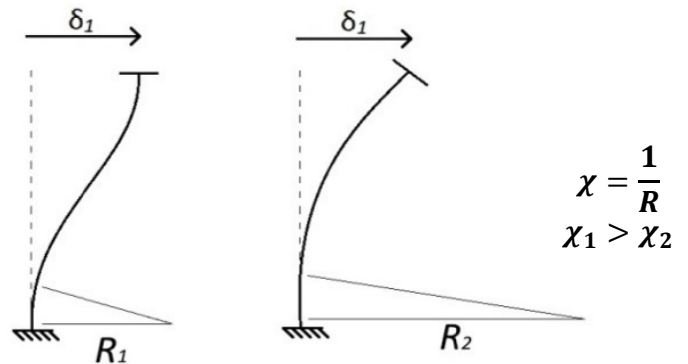

Fig. 7 Relative stiffness influence in sections curvature.

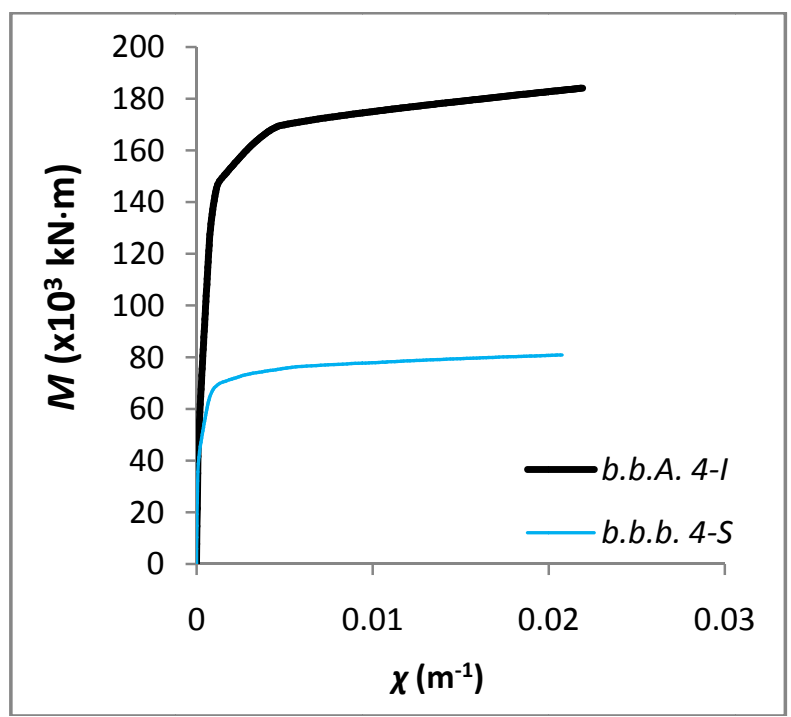

Fig. 8 Moment-curvature of sections.

We can see in Fig. 6 that the models, where Pier 4 is strongly armed, can support slightly larger displacements in the deck. This is due to the fact that Pier 4 exerts a great reaction on the deck causing smaller curvatures $\chi$, for the same top displacement $\delta_{1}$, as schematically represented in Fig. 7 for Element 2. Looking at Fig. 8, we can see that the capacity of cross-sections to take curvatures is much more dependent on the amount of reinforcement as already stated by Brito [10].

The rupture of sections is always due to exhaustion of deformability capacity in the steel. This is due to the significant low position of the neutral axis, a consequence of the low axial reduced load.

For the target displacement, the second steel layer of the secondary piers never yield. However, for the models with low reinforcement, the yielding is attained because the elements are subjected to larger curvatures (schematically represented in Fig. 7), by Element 1 in contrast with Element 2. On the other hand, for those highly reinforced piers, there is no yielding.

In Fig. 9, we can see the distribution of axial stresses in the upper cross-sections of Piers 2 and 4 for the b.b.b. model. The solid lines represent stresses in concrete and the dots represent stresses in the reinforcement bars. Referring to cross section in Pier 2, we can see that the reinforcement bars in compressed flange are still not yielding, implying that Pier 2 still keeps a considerable capacity for load carrying.

Loads acting at critical sections of models b.b.b. and b.b.A., including their kinematical state, are presented

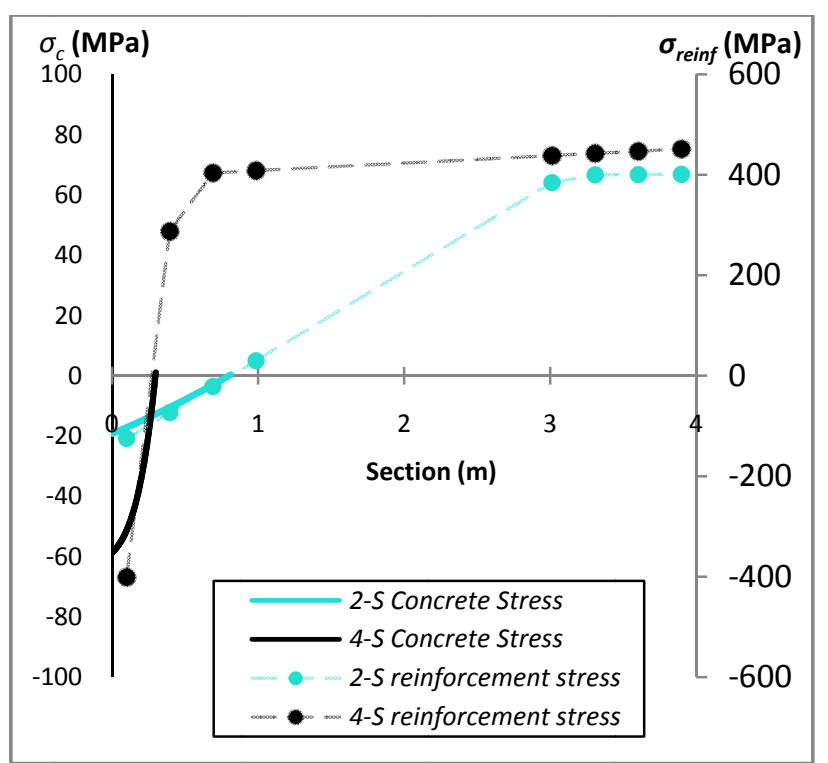

Fig. 9 Stress in concrete (solid line) and in reinforcement bars (dots) superior sections of Piers 2 and 4. 
Table 5 Loads acting in performance displacements.

\begin{tabular}{llllllllll}
\hline Model & Section & $M_{o b}(\mathrm{kN} \cdot \mathrm{m})$ & $N_{o b}(\mathrm{KN})$ & $V_{o b}(\mathrm{kN})$ & $\eta_{o b}(\%)$ & $\chi_{o b}(\% \mathrm{~m} / \mathrm{m})$ & $L N_{o b}(\%)$ & $\varepsilon_{y, o b}(\%)$ & $\varepsilon_{c, o b}(\%)$ \\
\hline \multirow{3}{*}{ b.b.b. } & $4-\mathrm{I}$ & 88,579 & $-33,504.3$ & \multirow{2}{*}{$6,465.6$} & 9.8 & 12.63 & 9.1 & 44.6 & -4.6 \\
& $4-\mathrm{S}$ & 79,198 & $-27,965.4$ & & 6.0 & 14.85 & 7.5 & 53.5 & -4.4 \\
& 2-S & 64,421 & $-26,179.7$ & $2,686.1$ & 5.6 & 0.87 & 20.3 & 2.7 & -0.69 \\
\hline \multirow{3}{*}{ b.b.A. } & 4-I & 173,561 & $-34,268.6$ & \multirow{2}{*}{$13,310.1$} & 10.0 & 8.32 & 14.2 & 27.7 & -4.7 \\
& 4-S & 163,683 & $-28,564.6$ & & 6.1 & 6.34 & 13.4 & 21.3 & -3.4 \\
& 2-S & 64,048 & $-26,330.6$ & $2,677.8$ & 5.6 & 0.83 & 20.9 & 2.5 & -0.74 \\
\hline
\end{tabular}

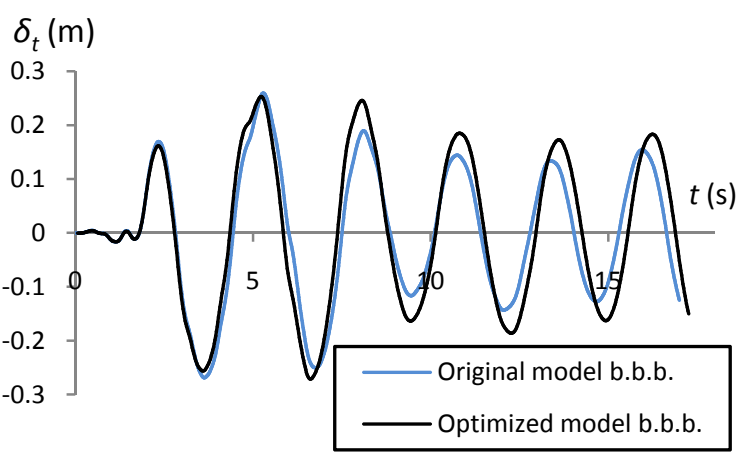

Fig. 10 Time-history of deck displacement.

in Table 5. Once the performance displacements are identical, we observe that not even the increase in steel reinforcement in Pier 4 influences the efforts and deformations of cross-sections of secondary piers and vice versa.

This means that these efforts and deformations of Pier 4 vary quite slightly with the amount of reinforcement.

\section{NLDA (Non-linear Dynamic Analysis)}

In this section, a non-linear dynamic analysis of the models defined in Section 3 is made in SeismoStruct [8] by applying a set of acceleration time history records. Six records were synthetically generated and adjusted to the linear spectral shape defined in Section 3. The records are applied at the foundation level of the three central piers in the longitudinal direction. The analysis of the response of each one of the four models is made for the six accelerograms in a total of 24 cases.

The basic target configuration used for comparing results is the horizontal displacement of the deck. Nonetheless, there is another important configuration at the level of the secondary piers. This latter phenomenon is more visible for the models with lower reinforcement in these piers. This occurs due to the high flexibility of these piers, moving in higher modes, but not constraining the overall base configuration. On the sequence of a preliminary study of the consequences, one concludes that the curvatures and extensions in the steel in the sections along the height of the piers do not overpass $\chi=7 \% / \mathrm{m}$ and $\varepsilon_{y}=25 \%$, respectively. Those modes introduce the presence of noise in the overall hysteretic curves. In order to have a measure of the total hysteretic damping coming from the non-linear behavior, filtering was applied to the system by creating an optimal model with null mass in the piers but warranting that the total dynamic mass was the same. As an illustration, Fig. 10 shows the time history of displacements and the hysteretic curves for models $b . b . b$., both the optimized and the original ones under the same accelerogram. The optimized models present similar maximum displacements and similar apparent periods of vibration to the values obtained with the original models. For this reason, the optimized models seem to be good representations of the original ones, but without noise.

As referred above, an analysis of the 24 cases of optimized models is presented below, considering the maximum displacements and the base shear. The concept of secant period $T_{s}$ is introduced as the period of an elastic structure with a secant stiffness obtained from the stage force-displacement at maximum. In parallel, the apparent period $T_{a}$ is also introduced as the value obtained from the main periodicity observed in the response time history of each run.

Table 6 presents the average response of all six input 
Table 6 Maximum base shear and deck displacement.

\begin{tabular}{llllll}
\hline Model & $\overline{V_{\max }}(\mathrm{kN})$ & $\overline{\delta_{\max }}$ & $(\mathrm{m})$ & $\bar{T}_{s}(\mathrm{~s})$ & $\overline{T_{a}}(\mathrm{~s})$ \\
\hline b.b.b. & $12,769.8$ & 0.25 & 3.2 & 2.9 \\
A.A.b. & $14,544.2$ & 0.26 & 3.0 & 2.8 \\
b.b.A. & $19,094.2$ & 0.24 & 2.5 & 2.4 \\
A.A.A. & $20,735.2$ & 0.24 & 2.5 & 2.4 \\
\hline
\end{tabular}

Table 7 Damping coefficient due to hysteretic behavior.

\begin{tabular}{lllll}
\hline Model & $n$ & $E_{D}(\mathrm{kN} \cdot \mathrm{m})$ & $\xi_{h}$ & $\xi$ \\
\hline b.b.b. & 5.5 & $6,154.9$ & 0.31 & 0.36 \\
A.A.b. & 6.0 & $6,729.6$ & 0.29 & 0.34 \\
b.b.A. & 5.5 & $16,780.4$ & 0.58 & 0.63 \\
A.A.A. & 5.5 & $16,751.4$ & 0.53 & 0.58 \\
\hline
\end{tabular}

Table 8 Values obtained in different analyses made.

\begin{tabular}{llll}
\hline Analyses & DLA & NLSA & DNLA \\
\hline$\delta_{t}(\mathrm{~m})$ & 0.19 & 0.22 & 0.24 \\
$V(\mathrm{kN})$ & 12,893 & 18,506 & 19,094 \\
$\beta$ & 0.08 & 0.12 & 0.12 \\
\hline
\end{tabular}

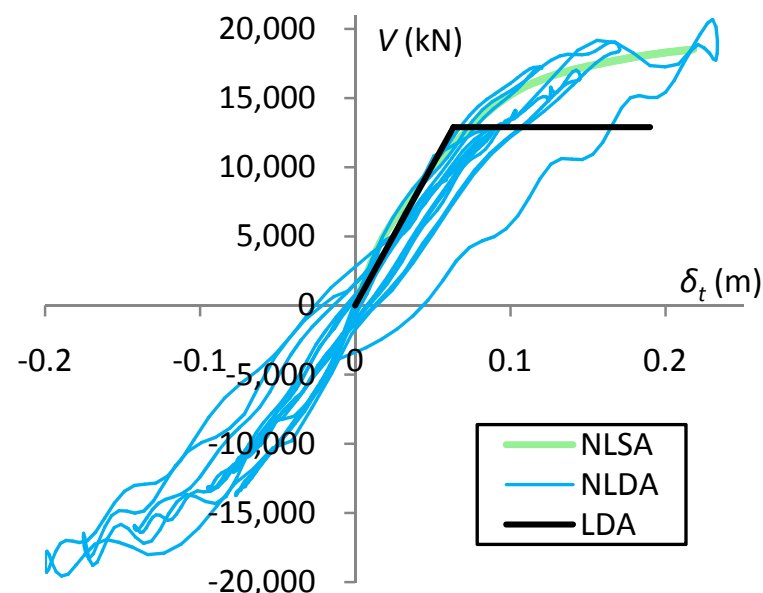

Fig. 11 Capacity curves for the different analyses made.

accelerograms for each model under study.

It should be noted that the scatter associated to the response values is quite high, attaining in one case the value of $0.29 \mathrm{~m}$ for displacement. Nevertheless, the hypothesis of "equal displacements" stands if we consider that maximum difference between maximum displacements in all cases is smaller than $80 \%$.

Next, the analysis of hysteretic curves is made for each case. To estimate the overall area of hysteretic damping dissipation, an envelope of all responses was determined. The area inside the envelope represents an upper estimative of the maximum energy dissipated per cycle and the total energy dissipated is only this one multiplied by the number of effective cycles. And a cycle is considered an effective cycle if the deck surpasses the yielding defined in the non-linear static analysis.

Damping coefficient due to hysteretic behavior $\left(\xi_{h}\right)$ is given by the following equation:

$$
\xi_{h}=\frac{E_{D}}{4 \pi} \frac{2}{V_{\max } \delta_{\max }} \cdot n
$$

A summary of damping coefficients from hysteretic phenomena is presented in Table 7.

\section{Conclusions}

The various analyses reported in this paper were made with the main objective of deepening the knowledge of the seismic behavior of a bridge with different pier heights, in which concerns the deformation capacity of their component elements and in the factors that may alter that capacity. To achieve this objective, a first linear analysis of an existing bridge was made leading to the steel design of critical cross-sections warranting the ultimate limit state. Subsequently, a study of sensitivity on the amount of steel reinforcement to be used was made. This study, with four different cases, involves non-linear static and dynamic analyses.

One of the cases, b.b.A., was selected as having the same distribution of steel reinforcement of the linear case to serve as comparison with the other three models. Considering that the non-linear dynamic analysis is the one that better represents the reality, being the others' (simpler models) approximations to the reality, the values obtained with the first one are always slightly above the others, causing some perplexity if only the simpler models are used. The case under analysis is one deserving a better understanding of the entire behavior. In Table 8 , it is presented the forces and displacement obtained in the different analysis made. Fig. 11 shows a comparison of the capacity curves derived with the various methods referred. The main difference is on the capacity curve of the linear analysis that 
underestimates the other ones.

As such, it was concluded that the behavior coefficient selected for the linear analysis based on EC8-2 $(q=3.0)$ is not a good representation for this bridge, once the $\mathrm{N} 2$ method leads to only half of that value. This suggests this type of bridge be considered as an inverted pendulum as the behavior is almost governed by Pier 4. In this sense, it is recommended that the behavior coefficient, according to EC8-2, should consider the participation of the various piers and their connection type to the deck, and not only the type of global structural system of the bridge.

Another parameter to take into consideration is the plasticity factor that may inform on the importance of the components with less degree of participation.

It became clear that the curvature capacity of these short piers is very much conditioned by the rupture of the steel, but the ultimate curvature is not much influenced by the amount of steel.

As far as the structural solution is concerned, it can be optimized without touching the adopted aesthetics. The recommendation goes to create a hinge at the connection of Pier 4 to the deck. This way, it is possible to assure that the curvature depends only on the top displacement, which, for very flexible structures, does not depend on the longitudinal stiffness. The second alteration has something to do with the adoption of cross-sections with clear bending dependence with smaller depths at the bottom of the taller piers.

From this study, which only considers the seismic load, one can conclude that the longitudinal seismic analysis of this type of structures should be made exclusively based on the small pier, due to the fact that, whatever exploitation of the resistance of the longer piers, the participation of the small pier is predominant in the overall response.

\section{References}

[1] RSA. 1983. Regulamento de Segurança e Acções para Estruturas de Edificios e Pontes (Code of Safety and Seismic Actions for Buildings and Bridges), Dec 238/83, Imprensa Nacional. (in Portuguese).

[2] EN (European Norm). 2004. EC-8-1. Eurocode 8: Design of Structures for Earthquake Resistance-Part 1: General Rules, Seismic Actions and Rules for Buildings. Reference No. EN 1998-1:2003 E. Brussels: EN.

[3] Mander, J. P., Priestley, M. J. N., and Park, R. 1988. "Theoretical Stress-Strain Model for Confined Concrete." ACSE (Americna Society of Civil Engineers) Journal of Structural Engineering 114 (8): 1804-26.

[4] Menegotto, M., and Pinto, P. E. 1973. "Method of Analysis for Cyclically Loaded RC Plane Frames Including Changes in Geometry and Non-elastic Behaviour of Elements under Combined Normal Force and Bending." In Proceedings of Symposium on the Resisntance and Ultimate Deformability of Structures Acted on by Well Defined Loads, International Association for Bridge and Structural Engineering, 15-22.

[5] Computers and Structures, Inc. 2008. Integrated Structural Analysis and Design Software. Berkeley: Computers and Structures, Inc.

[6] DNA (National Document Application). 2011. Committee for the Application of EC-8 to Portugal. DNA.

[7] EN. 2005. EC-8-2. Design of Structures for Earthquake Resistance-Part 2: Bridges, Ref. No. EN 1998-2:2005 E. Brussels: EN.

[8] SeismoSoft. 2006. SeismoStruct ${ }^{\circledR}$. SeismoSoft. Accessed January 1, 2015. http://www.seismosoft.com.

[9] Fajfar, P. 2000. "A Nonlinear Analysis Method for Performance-Based Seismic Design." Earthquake Spectra 16 (3): 573-92.

[10] Brito, A. 2011. Dimensionamento de Estruturas Subterrâneas de Betão Armado Sujeitas a Acções Sísmicas. $\mathrm{Ph} . \mathrm{D}$. thesis, Instituto Superior Tecnico. (in Portuguese). 